Philipp Weber

\title{
Gleichgeschlechtliche Elternschaft im Internationalen Privatrecht
}

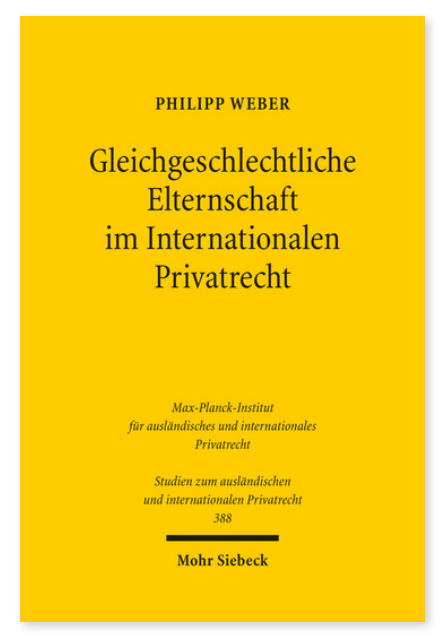

2017. XX, 256 Seiten. StudIPR 388

ISBN 978-3-16-155529-9

DOI 10.1628/978-3-16-155529-9

eBook PDF 79,00€

ISBN 978-3-16-155528-2

fadengeheftete Broschur 79,00€
Eine wachsende Zahl ausländischer Rechtsordnungen ermöglicht die gleichgeschlechtliche Elternschaft durch Anerkennung einer zweiten Frau neben der Geburtsmutter oder in Leihmutterschaftskonstellationen. Für den deutschen Rechtsanwender stellt sich die Frage, inwieweit eine derartige im Ausland begründete Abstammungszuordnung auch im Rahmen der deutschen Rechtsordnung Wirkung entfaltet. Ausgehend von einer rechtsvergleichenden Darstellung und Einordnung ausländischer Abstammungsregelungen zugunsten gleichgeschlechtlicher Eltern untersucht Philipp Weber grundlegende kollisionsrechtliche Fragen im deutschen Abstammungsrecht. Dabei berücksichtigt er verfassungsrechtliche und europarechtliche Vorgaben. Im Zuge dessen wird die aktuelle Rechtsprechung im Bereich des internationalen Abstammungsrechts dargestellt und analysiert.

Philipp Weber Geboren 1987; Studium der Rechtswissenschaften in Passau; Referendariat in Passau und Canberra; 2016 Promotion; seit 2016 Referent im Bayerischen Staatsministerium für Wirtschaft und Medien, Energie und Technologie.
Jetzt bestellen:

https://mohrsiebeck.com/buch/gleichgeschlechtliche-elternschaft-im-internationalen-privatrecht-9783161555299?

no_cache=1

order@mohrsiebeck.com

Telefon: +49 (0)7071-923-17

Telefax: $+49(0) 7071-51104$ 